\title{
Analysis of fumes emitted during hard facing of FCAW wires
}

\author{
Mithra S, Venkatakrishnan P G
}

${ }^{1}$ Department of Metallurgical Engineering, Government college of Engineering, Salem, India

\begin{abstract}
Flux Cored Arc Welding (FCAW) wires are widely used for hard facing as they provide high deposition efficiency, wear resistance and faster speed rates than the solid wire used in Gas Metal Arc Welding process. Flux Cored Arc Welding process employs cored electrodes which contain the fluxing agents, metal powder, deoxidizers and Ferro alloys which contribute the fume emissions during the welding operation. The flux ingredients used vary based on the applications. An open-arc FCAW wire developed for high temperature wear resistance applications comprise borides, carbides of iron based alloy system. A high level of smoke is generated during welding with this wire which reduces the weld pool visibility. The research work is carried out to reduce the emission of fumes up to 70-80\% (from present fume emission level) without affecting composition and wear behaviour of the alloy thereby making the wire environmental friendly.
\end{abstract}

Keywords-Carbides of iron based alloy system, Deoxidizers, Flux Cored Arc Welding, High temperature wear resistance, Weld pool visibility.

\section{INTRODUCTION}

The fumes generated during welding mainly come from the combustion of the volatile materials that is added during welding. The volatile material that is supplied to the welding is through flux material added to the welding process. Not in all welding process flux is added, they are generally added in the consumable welding process such as Shielded Metal Arc Welding (SMAW), Gas Metal Arc Welding (GMAW), Flux Cored Arc Welding (FCAW) and Submerged Arc Welding (SAW). These processes can be differentiated based on the way the flux is supplied. In SMAW flux is added in the form of coated electrode, in FCAW the flux is added in the form of cored electrodes, in GMAW, the consumable is in the form of solid wire whereas in SAW process granulated flux is used. In order to protect the arc the external shielding medium is provided. The external shielding medium not only provides stable operation but also provide shielding from external atmosphere to prevent contamination of the weld
A study was performed to investigate the factors contributing to the emission of welding fumes and the main factors that manipulate the fume formation are welding current, voltage, shielding gases, mode of metal transfer, and the chemical composition of the material welded. All such factors are interrelated and hence they influence one over the other. The influence of each factor on weld fume emission was explored to understand the most effective factors for minimizing the welding fumes.

The initial evaluation focused on determining the flux ingredients that are more in the fumes through X-RAY diffraction. The mode of metal transfer occurring during the process is viewed through high speed camera to find spray transition current at which reduced smoke level is obtained. The amount of fume emission is reduced by bringing the drop spray mode of metal transfer by varying the current parameter.

\section{LITERATURE REVIEW}

The welding process is accompanied by emission of fumes. In order to minimize the fumes emitted during welding a thorough knowledge regarding the factors that causing the welding fumes. The factors that contribute for the formation of the welding fumes are Electrode, Welding speed, Shielding gas, Welding processes, Welding parameters, Welding geometry and Base metal. Fume generation during welding can be reduced by controlling the factors that contribute the emission of welding fumes. From the study, it can be stated that influence of all the factors such as welding current, voltage, shielding gas and chemical composition on the fume generation, are interrelated. Moreover fume emission solely depends on these factors. Therefore it is necessary to choose a suitable combination of parameter for generating better mode of metal transfer.

\section{EXPERIMENTAL WORK}

To analyze the fumes a comparative study is made between two wires namely HPW and 6430 wire. The HPW wire is highly problematic as it emits enormous amounts of fume during applications. The properties of the wires are essential 
as it is widely employed for high temperature applications. Therefore it highly affects the weld pool visibility. but in case of 6430 wire the fumes are not much higher . the chemical composition of the wires are almost similar except some components. In order to fine the component which is emitting the following studies have been made.

\subsection{CHEMICAL COMPOSITION OF FCAW WIRES}

The comparison of chemical composition of the two wires are made in the following tables

Table.3.1: chemical composition of 6430 wire

\begin{tabular}{llc}
\hline S.no & $\begin{array}{l}\text { Name of the material in } \\
\text { power form }\end{array}$ & $\begin{array}{l}\text { Quantity } \\
\text { (weight \%) }\end{array}$ \\
\hline $\mathbf{1}$ & Boron carbide & $1-3$ \\
$\mathbf{2}$ & $\begin{array}{l}\text { Hydrocarbon ferro } \\
\text { chromium }\end{array}$ & $80-90$ \\
$\mathbf{3}$ & Graphite & $3-6$ \\
$\mathbf{4}$ & Ferro niobium & $2-4$ \\
$\mathbf{5}$ & Silicon carbide & $1-3$ \\
$\mathbf{6}$ & Ferro silicon zirconium & $1-3$ \\
\hline $\mathbf{7}$ & Sodium fluoride & $0.2-2$ \\
\hline
\end{tabular}

Table.3.2: Chemical composition of HPW wire

\begin{tabular}{llr}
\hline S.NO & $\begin{array}{l}\text { Name of the material (in } \\
\text { powder form) }\end{array}$ & $\begin{array}{c}\text { Quantity } \\
\text { weight \%) }\end{array}$ \\
\hline 1 & Ferro-Molybdenum & $\mathbf{1 0 - 1 4}$ \\
2 & Ferro-Niobium & $\mathbf{1 0 - 1 5}$ \\
\hline 3 & Tungsten carbide & $\mathbf{5 - 1 0}$ \\
4 & Boron carbide & $\mathbf{7 - 1 2}$ \\
\hline 5 & Ferro-chromium & $\mathbf{8 - 1 2}$ \\
\hline 6 & Manganese & $\mathbf{1 - 5}$ \\
7 & Chromium & $\mathbf{2 0 - 3 0}$ \\
\hline 8 & Ferro-Titanium & $\mathbf{1 - 4}$ \\
\hline 9 & Ferro silicon manganese & $\mathbf{1 - 3}$ \\
10 & Ferro silicon zirconium & $\mathbf{1 - 3}$ \\
\hline 11 & Chromium Nitride & $\mathbf{4 - 6}$ \\
12 & Fluorspar & $\mathbf{0 . 2 - 2}$ \\
\hline 13 & Sodium fluoride & $\mathbf{0 . 2 - 2}$ \\
\hline
\end{tabular}

Table.3.3: Comparison of two wires

\begin{tabular}{ll}
\hline HPW WIRE & 6430 WIRE \\
\hline Hardness HRc 65 & $\begin{array}{l}\text { Hardness HRc 60 } \\
\text { High temperature wear } \\
\text { Ambient temperature } \\
\text { application }\end{array}$ \\
$\begin{array}{l}\text { High fume level and } \\
\text { poor weld pool visibility }\end{array}$ & $\begin{array}{l}\text { Common as in other } \\
\text { welding process }\end{array}$ \\
\hline
\end{tabular}

\section{WELD BEAD OF 6430 WIRE}

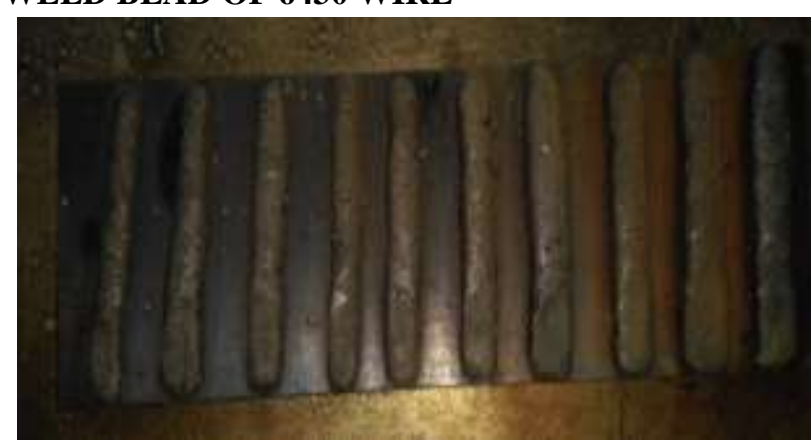

Fig.1: Weld bead of 6430 wire

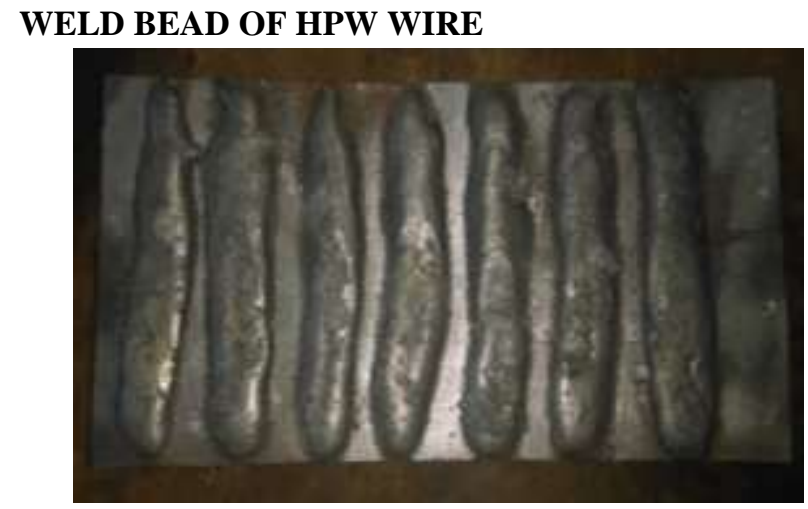

Fig.2: Weld bead ofHPWwire

\subsection{VARIATION OF WELD BEAD SIZE WITH CURRENT}

The bead size generally increases with the increase in the current. The spatter is enormous in case of HPW wire and over a particular range of current the spatter is found to decrease and the fume is also reduced over that range 

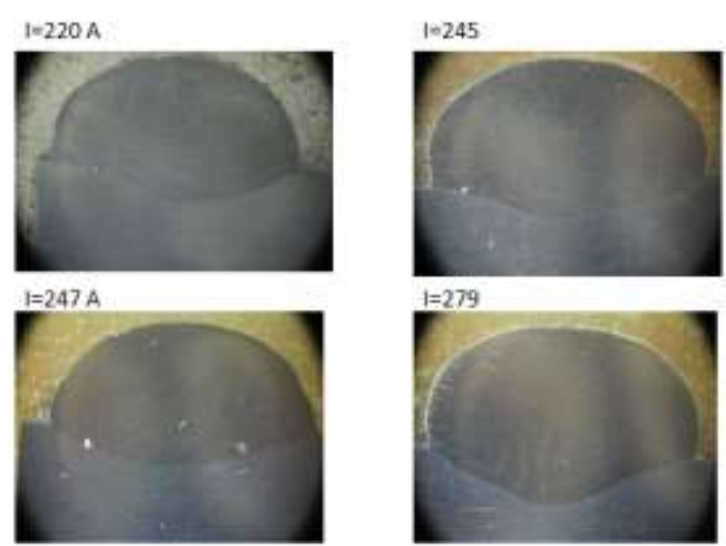

Fig.3: Variation of weld bead size with current

\subsection{METALLOGRAPHIC EXAMINATION}

The weld beads are sectioned and examined metallographically. The samples are emery polished first and then with cloth polishing. The etchant used is pikral and the etching time is 10 to 15 seconds. The micrographs obtained from 6430 and HPW flux cored wires are shown in the figure 4 and 5

MICROSTRUCTURE OF HPW WIRE

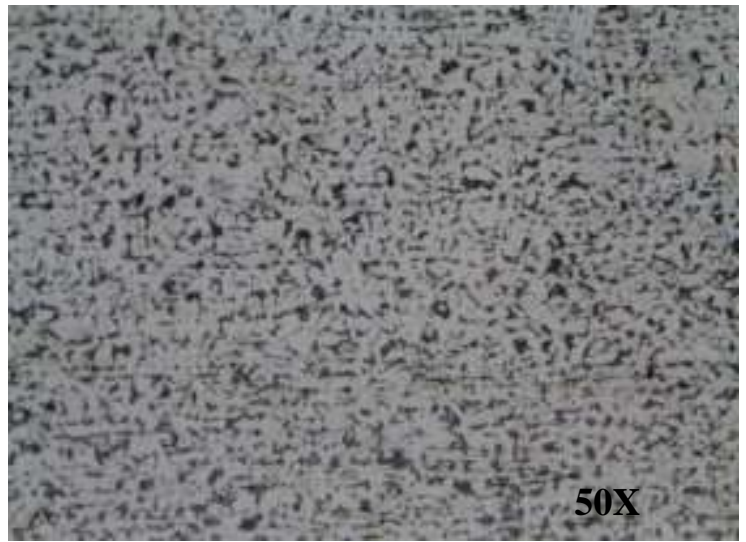

a) Base Metal

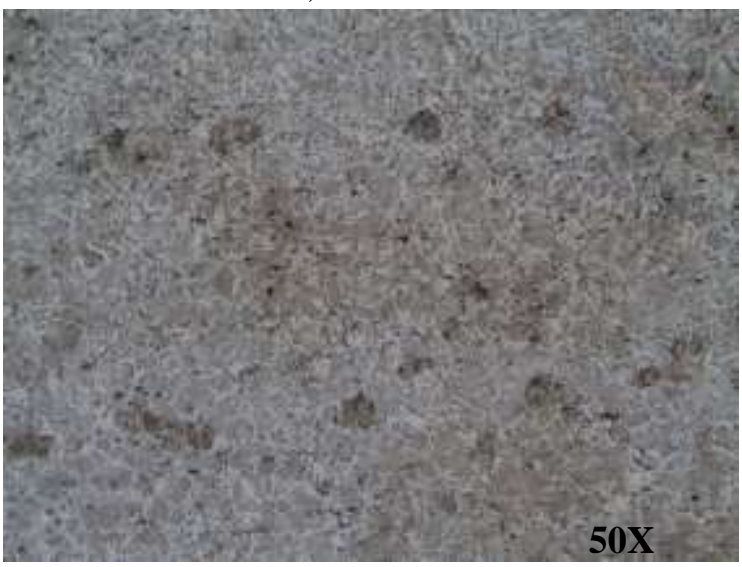

b) Heat affected Zone

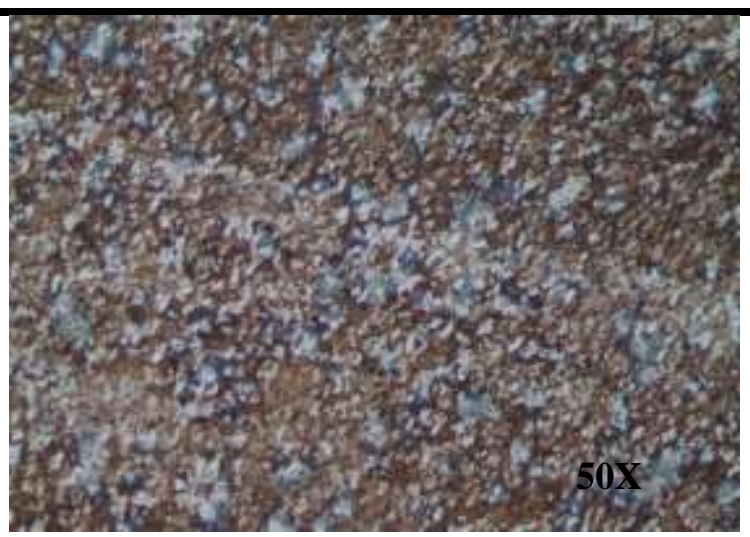

c) Weld metal

Fig.4: Microstructures of 6430 wire

\section{MICROSTRUCTURE OF HPW WIRE}

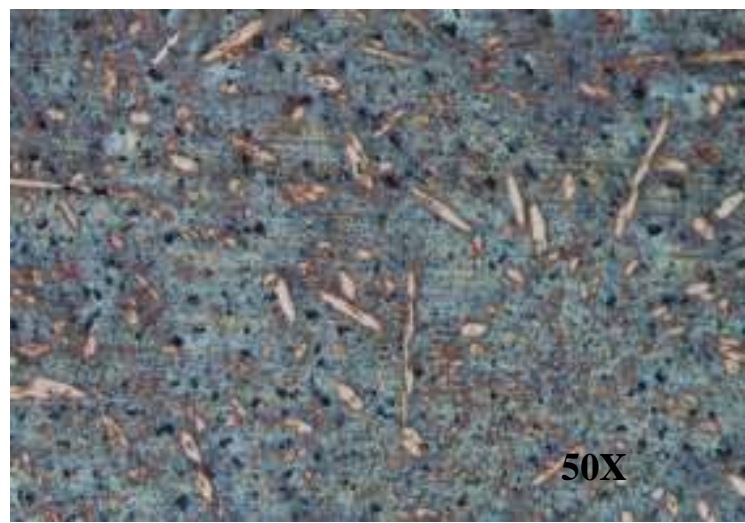

a) Weld Metal

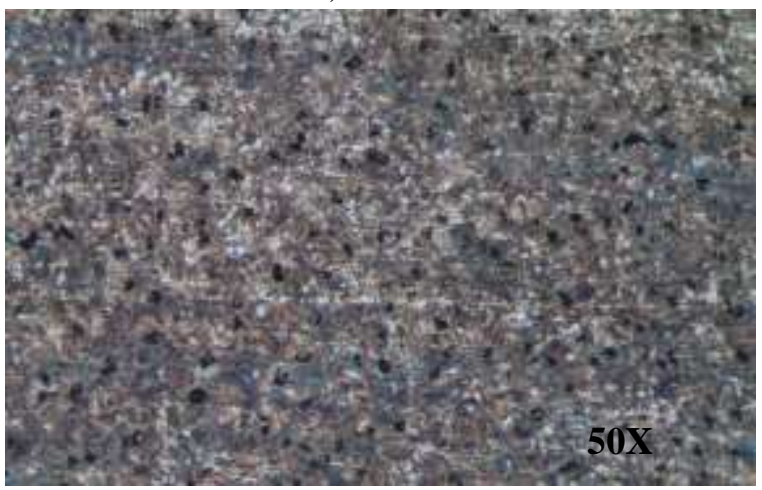

b)Heat affected Zone 


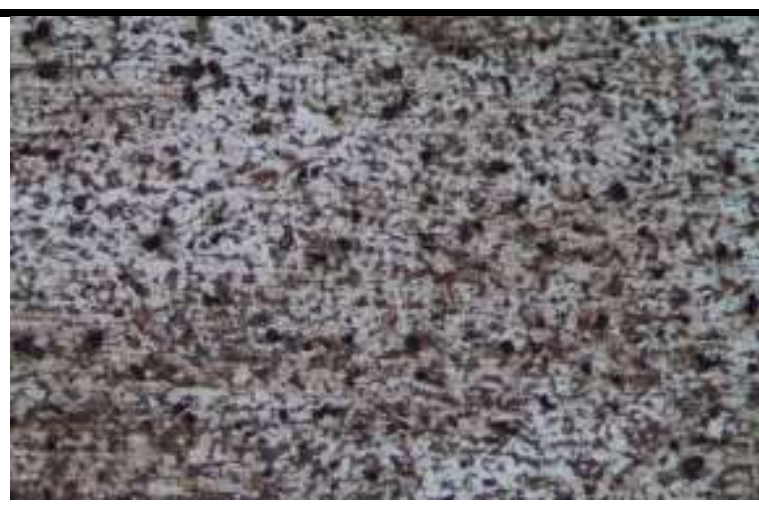

c)Base metal

Fig. 5: Microstructures of HPW wire

From the micrographs it can be inferred that base metal is mild steels and weld bead gives superior martensitic microstructure and HAZ is superior in case of HPW wire than the 6430 wire the proximity to cracks are limited in case of HPW wire. Hence HPW wire has superior properties when compared with 6430 wire

\subsection{RAY DIFFRACTION}

The fumes of HPW wire and 6430 wire are collected using vacuum pump and are examined for X RAY diffraction. The Xray diffraction is done in D8 BRUKER axswith copper $\mathrm{k}$ alpha radiation.

\section{HPW FLUX VS FUMES}

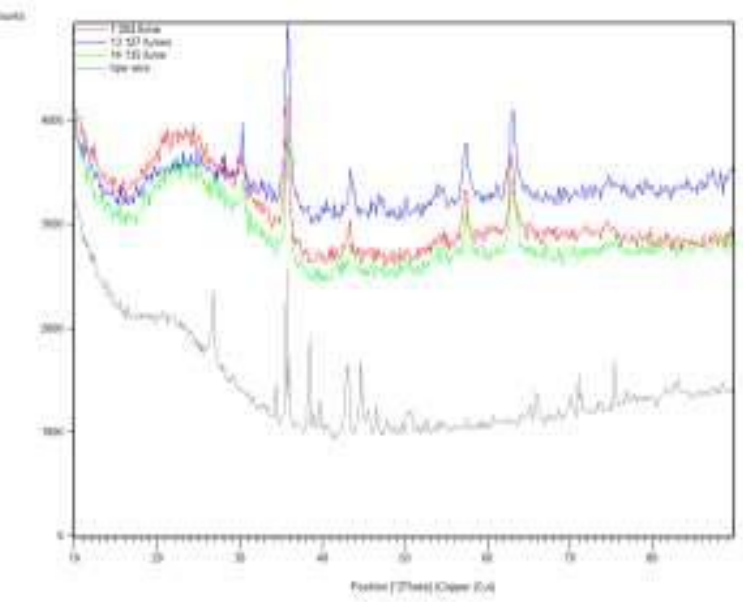

Fig.6: X ray graph of HPW flux and fumes

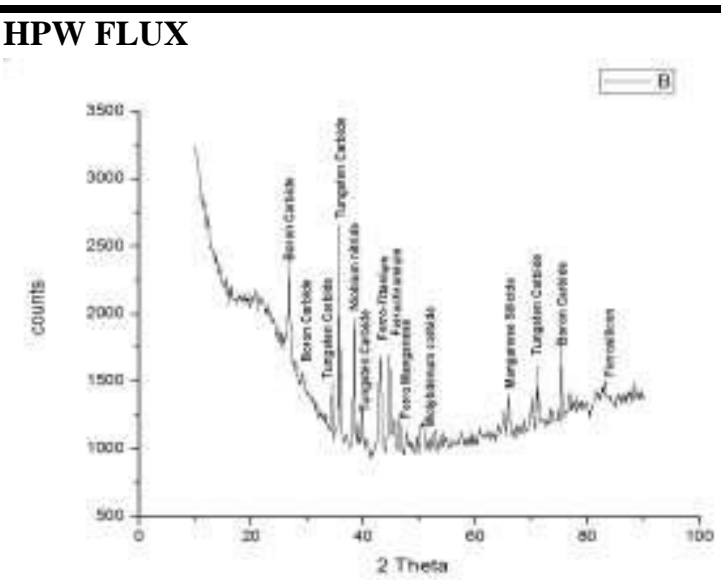

Fig.7: X ray graph of HPW flux

\section{HPW FUMES}

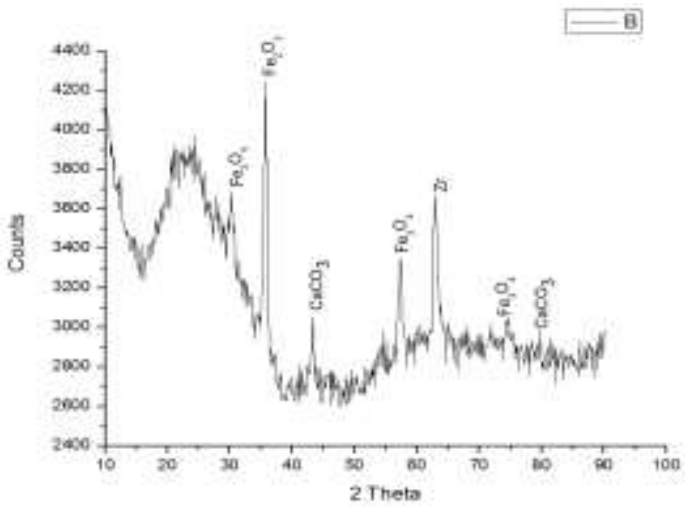

Fig.8: X ray graph of HPW fume

\section{FLUX VS FUMES}

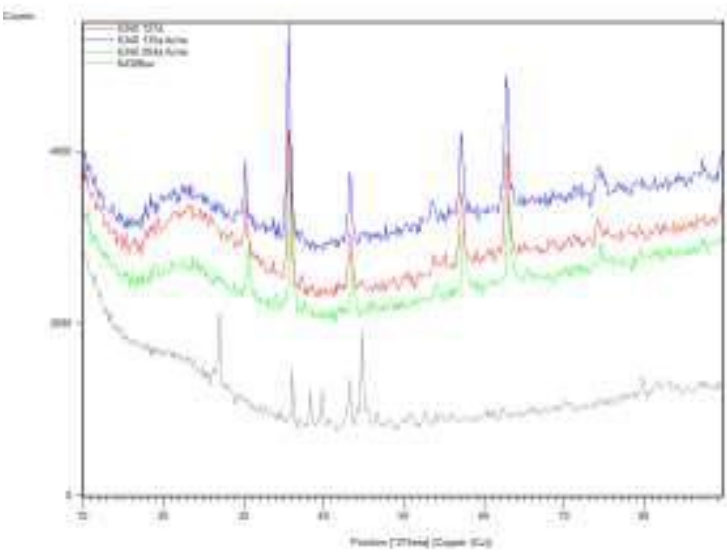

Fig.9: X ray graph of HPW fume 


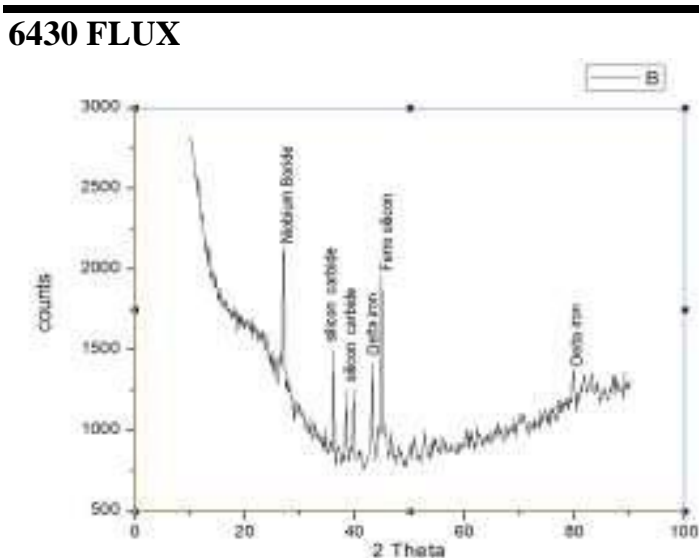

Fig.10: $X$ ray graph of 6430 flux

\section{FUMES}

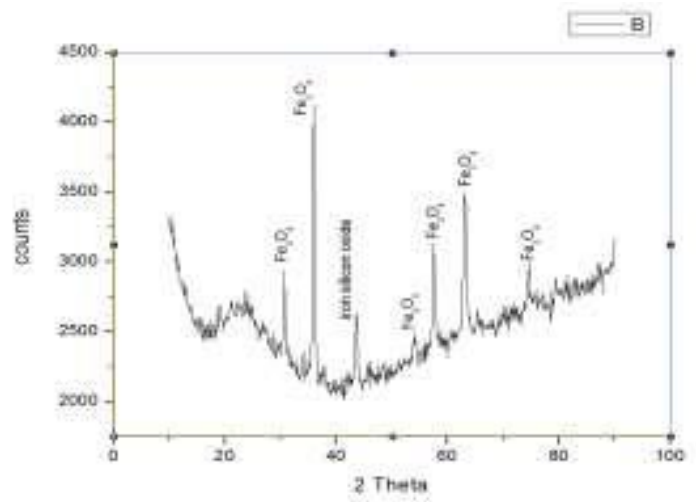

Fig.11: X ray graph of 6430 fume

From the graph it has been found that the most emitting component in HPW wire is $\mathrm{Fe}_{2} \mathrm{O}_{3}$ which is not emitted in the 6430 wire. So the reason behind the fumes in HPW wire is $\mathrm{Fe}_{2} \mathrm{O}_{3}$. The chemistry behind the fume emission has to be analyzed.

\section{CONCLUSION}

From the various analyses the problematic wire HPW is superior in its properties. But its fume emission is the only problem that restricts the usage of such wire. So its fume emission should be reduced through optimizing the current parameter but not with changing the chemical composition of the flux as it plays a major role in their properties.

\section{REFERENCES}

[1] Carpenter K.R., Monaghan B.J. and Norrish J.(2009), 'Influence of Shielding Gas on Fume Formation Rate For Gas Metal Arc Welding of Plain Carbon Steels', ASM international, $\mathrm{p} 436-442$
[2] Den Ouden G, Hermans M.J.M. (2009), "Welding technology", Delft University of technology.

[3] Eagar T.W and Kim Y.S (1993), 'Metal transfer in pulsed current GMAW', Welding Journal Vol. 72 No.6 PP. 279-287

[4] Geoffrey Slater (2004), 'Weld Fume Plume Dispersion', University of Wollongong, theses 384.

[5] Haidar J and Lowke J J (1997), 'Effect of CO2 shielding gas on metal droplet formation in arc welding', IEEE Trans. Plasma Sc. Vol.25 No.5, P931936

[6] Heile R. F., and Hill D.C (1975), 'Particulate fume generation in arc welding processes', Weld. J., 54, 201s-210s

[7] Hermans M.J.M, Den Ouden G (1999), 'Process behavior and stability in short circuit gas metal arc welding', Weld J 78(4):137-141

[8] Ian Richarclson, John Norrish and Marcel Hermans (1989) 'The mechanism and significance of drop spray transfer in GMAW', International Institute of Welding, IIW-1893-06.

[9] Ines Pires, Luisa Quintino, Victor Amaral (2010), Tobias Rosado, 'Reduction of Fume And Gas Emissions Using Innovative Gas Metal Arc Welding Variants', International journal for advanced manufacturing technology, 50:557-567.

[10] John Norrish (2006), 'Advanced welding processes, Technologies and process control', Institute of Physics Publishing.

[11] Lancaster J F (1986), 'The physics of welding', 2nd Edition, Pergamon Press, ISBN 0-08-034076-8, p246.

[12] LevchenkoO.G(1998), 'Methods of reducing the generation of the welding fumes', Welding international 1998 12(9) 747-752. 